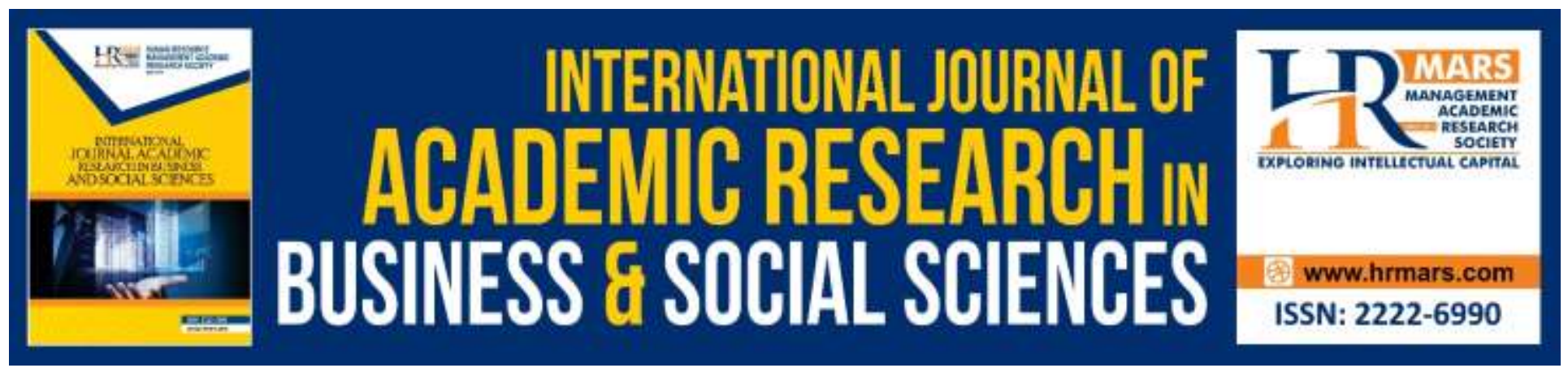

\title{
Skipping Breakfast and Lack of Physical Activity: Contributing Factors of Depressive Symptoms among University Students
}

Asma Perveen, Hazalizah Binti Hamzah, Fatanah Ramlee, Ebru Morgul, Priyalatha Govindasamy

To Link this Article: http://dx.doi.org/10.6007/IJARBSS/v8-i8/4427

DOI:10.6007/IJARBSS/v8-i8/4427

Received: 06 July 2018, Revised: 19 July 2018, Accepted: 27 July 2018

Published Online: 17 August 2018

In-Text Citation: (Perveen, Hamzah, Ramlee, Morgul, \& Govindasamy, 2018)

To Cite this Article: Perveen, A., Hamzah, H. B., Ramlee, F., Morgul, E., \& Govindasamy, P. (2018). Skipping Breakfast and Lack of Physical Activity; Contributing Factors of Depressive Symptoms among University Students. International Journal of Academic Research in Business and Social Sciences, 8(8), 12-23.

Copyright: (C) 2018 The Author(s)

Published by Human Resource Management Academic Research Society (www.hrmars.com)

This article is published under the Creative Commons Attribution (CC BY 4.0) license. Anyone may reproduce, distribute, translate and create derivative works of this article (for both commercial and non-commercial purposes), subject to full attribution to the original publication and authors. The full terms of this license may be seen at: $\underline{\text { http://creativecommons.org/licences/by/4.0/legalcode }}$

Vol. 8, No. 8, August 2018, Pg. $12-23$

Full Terms \& Conditions of access and use can be found at http://hrmars.com/index.php/pages/detail/publication-ethics 


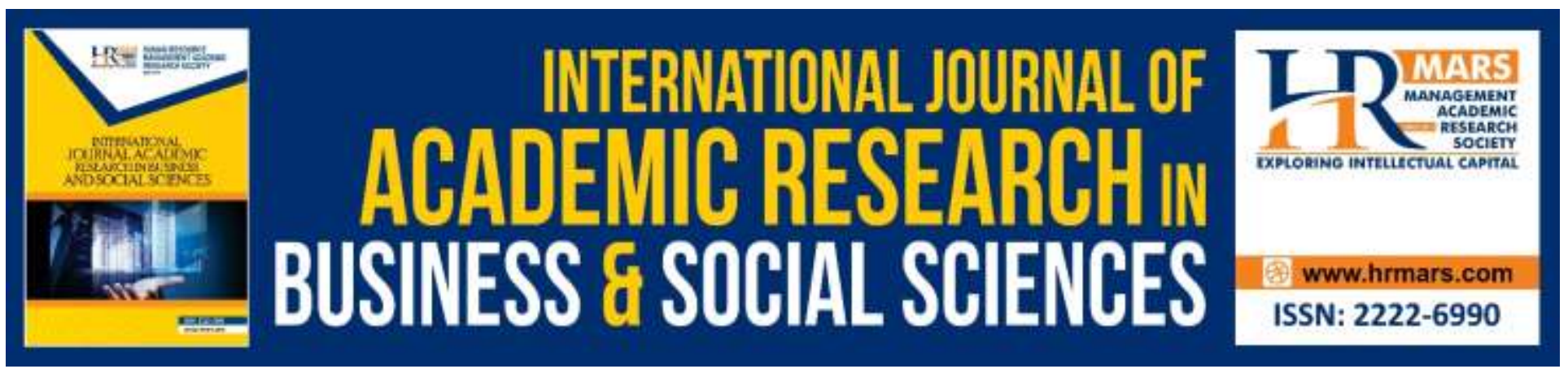

\title{
Skipping Breakfast and Lack of Physical Activity: Contributing Factors of Depressive Symptoms among University Students
}

\author{
Dr. Asma Perveen, Dr. Hazalizah Binti Hamzah, Dr. Fatanah \\ Ramlee, Dr. Ebru Morgul, Dr. Priyalatha Govindasamy \\ Senior Lecturer, Sultan Idris Education University, Malaysia
}

\begin{abstract}
In Education sectors many researchers have focused student's life style and effects on mental health. Currently there are many factors which are contributing to develop depressive symptoms among University Students. Study was conduct to investigate the relationship between skipping breakfast and lack of physical exercise are contributing risk factor of depression among University students. To conduct this survey research, sample $(\mathrm{N}=350)$ students participated from different faculties, of Sultan Idris Education University (UPSI), Malaysia. Students (178\% male, 172\% female), age (19-27 years) were selected by using convenience sampling. This survey was conduct by administering the structured questionnaire of Breakfast information and Habitual physical exercise questionnaire, level of depression was measured by Beck Depression Inventory (Beck, et al., 1996). Results revealed that there was strongly negative correlation between the scores of having breakfast, Habitual physical activity and depression. Multiple regression shows that skipping breakfast and lack of physical activities were significant, $F(2,347=87.99, p<.000), R^{2} 33 \%$, which revealed skipping breakfast and physical activity are significant at $(p<.000)$. Result indicate that skipping breakfast and lack of physical activity can predict depression. Student's life style behavior of skipping meal and lack of physical are significant for mental and emotional health. Present research predict that skipping breakfast, lack of physical exercise are risk factors toward depression among students. This study is important to learn about the contributing factors of mental health, we can encourage students to take healthy and timely meal and participate regularly in exercise to increase mental health.
\end{abstract}

Keywords: University Students, Skipping Breakfast, Depression, Physical Activity, Depression.

Introduction

Lifestyle behaviours like poor diet and physical inactivity are identified as health-risk behaviours (World Health Organisation, 2010). The lifetime prevalence of MDD is $10-25 \%$ for women, and $5-12 \%$ for men (Rihmer \& Angst, 2004). According to the World Health Organization (WHO, 2015), it is also the most important precursor of suicide and will be the second cause of Global Disease Burden by the year 2020, WHO states that the burden of depression is $50 \%$ higher for females than 
INTERNATIONAL JOURNAL OF ACADEMIC RESEARCH IN BUSINESS AND SOCIAL SCIENCES

Vol. 8, No. 8, August 2018, E-ISSN: 2222-6990 @ 2018 HRMARS

males and Indians are reported to be among the world's most depressed. The prevalence of depression is $9 \%$, of major depressive episode is $36 \%$, and the average age of onset of depression is 31.9 years, in India. (The world health report, 2014)

Several studies have focused on the advantages of breakfast eating. Timely taken breakfast help the good energy level to focus and stay productive. The benefits include providing the human body with nutrients necessary for optimal growth and development (Rampersaud, 2009), as well as fibers, an important source of vitamins and minerals (Nicklas, Reger, Myers, 2000). In addition, students, whether children or adolescents, who regularly eat breakfast enjoy greater achievements in University, have higher academic performance, and show lower absenteeism, (Williams, 2007) as they have less risk of catching a cold, or of having chronic illness (Fujiwara, 2007).

In light of such benefits, there is an intensive need to clarify the correlates of breakfast eating or skipping. As studies found that adolescents have higher rates of breakfast skipping compared with children (Deshmukh-Taskar, 2010), University students were targeted as participants in the study Dietary patterns vary from one country to another with variations in sociocultural characteristics, economic conditions, and availability of school meal programs (Vereecken et al, 2010). A few studies, which mainly focused on Asian populations, investigated the relationship between socioeconomic and lifestyle factors and breakfast eating/skipping. Study was aimed to assess the predictors of breakfast eating or skipping in a sample of young Saudi women; where breakfast eating was defined as eating a morning meal at home (Rahkonen et al, 2003). Student's life is very demanding and they are facing many challenges at same time. So not taking proper meal, especially skipping breakfast and doing no physical exercise can increase the stress and negative emotions like anxiety and depression.

Our present generation is growing faster and looking for easy way to live and eat, so mostly they are eating outside, from restaurants or shops burger, hardly students find time to find healthy meal or to cook meal at home. Consequently, they may select breakfast skipping as a form of dieting (Bruening et al, 2013). This suggests that breakfast skipping can be solved through an integrated approach that addresses, in addition to adolescents themselves, their parents and peers. Moreover, it was proved that breakfast eaters have a higher daily energy intake compared with breakfast skippers, and hence the positive association between breakfast skipping and other mental health issues (Hussein et al, 2013). Present mental health issues among studnts are indicating to promote a healthy studnts life style behaviours.

Allgöwer, Wardle, \& Steptoe (2001) investigated the relationship of depressive symptoms, social support, and a range of personal health behaviours in 2,091 male and 3,438 female university students from 16 countries. Depressive symptoms and social support were measured using the short Beck Depression Inventory and the Social Support Questionnaire; personal health behaviours were also assessed. Age, social support, and clustering by country into account, depressive symptoms were significantly associated with lack of physical activity, not eating breakfast, irregular sleep hours, and not using a seat belt in both men and women, and additionally with smoking, not eating fruit, and not taking proper meal with lack of physical exercise (Barton et al, 2005). Low social support was independently associated with lack of physical activity, stress and depression.

Geoff at al. (2014) revealed in a study about students unhealthy life patterns and mental health problems. The study revealed that transitioning to university involves a major life change that can have implications for physical and mental health. This study had three objectives: first, assess the mental health and health behaviour participation of Australian university students; second, evaluate clustering of health behaviours; and third, examine how mental health relates to health behaviours. 
University students of Australian regional university completed an online survey containing the Depression, Anxiety, and Stress Scales and a health behaviour questionnaire. Over one third of students reported mild or higher mental illness symptoms and most reported engaging in multiple unhealthy behaviours. Mental health was associated with unhealthy behaviours. For males, depressive symptoms were associated with skipping breakfast and poor habits of physical activities.

Lim et al, (2012) revealed that students have tendency to skip their meal. The research results revealed that depressive symptoms were associated with skipping breakfast, inadequate vigorous physical activity, and short or long sleep hours. Stress symptoms in females were associated with healthy sleep hours, but poor sleep quality. Future research may consider whether an intervention targeting one or two key health behaviours has utility in improving participation in other health behaviours and mental health.

Supa et al. (2015) revealed in a study that the prevalence of physical inactivity was $41.4 \%$, ranging from $21.9 \%$ in Kyrgyzstan to $80.6 \%$ in Pakistan. In multivariate logistic regression, older age (22-30 years), studying in a low- or lower middle-income country, skipping breakfast and lack of social support were associated with physical inactivity. In men, being underweight, being overweight or obese, not avoiding fat and cholesterol, not having severe depression symptoms, low beliefs in the health benefits of physical activity, low personal control and knowledge of exercise-heart link, and in women, not trying to eat fibre, low personal mastery and medium personal control were additionally associated with physical inactivity.

The research review concluded that there is significant relationship between skipping breakfast and lack of physical activity with depression. It's only recently that people have begun to see the link between physical activity and mental health, and it is important for increasing people's self-esteem, general mood, coping with stress and depression. We now have very strong evidence that physical activity can prevent depression. There are a very few researches on life style aspects and their mental health issues of students in Malaysia. This present study is significant contribution to highlight the healthy meal intake and promoting physical activities to increase mental health. This study highlight that life style behaviours by taking healthy breakfast, doing regular exercise can promote good mental health among students.

\section{Method}

Research design was cross sectional survey method, study was conduct in Sultan Idris Education University. The sample was selected from all the faculties randomly. ( $N=350)$ students randomly participated in the research, within the age (Mean=22.37) range (19- 27 years). Both male and female students participated in research. Ethical concern was followed with informed consent and confidentiality assurance.

This survey was conduct by administering the structured questionnaire of Breakfast information, $1=$ ( missed more than three time in a week) , $2=$ (never skip breakfast) and for the physical activity, Godin Leisure - Time questionnaire was administered, level of depression was measured by Beck Depression Inventory (Beck, 1996). The collected data was analyzed by using statistical method of correlation and regression.

\section{Results and Discussion}

According to descriptive analysis, gender distributions, male $(\mathrm{N}=178)$, Female $(\mathrm{N}=172)$.

Students participated from 18 departments of Sultan Idris Education University. According to reported information's, marital status $(\mathrm{N}=343)$ were single and $(\mathrm{N}=7)$ were married. Most of the 
INTERNATIONAL JOURNAL OF ACADEMIC RESEARCH IN BUSINESS AND SOCIAL SCIENCES

Vol. 8, No. 8, August 2018, E-ISSN: 2222-6990 @ 2018 HRMARS

students were reported Malay $(\mathrm{N}=233)$, Chinese $(\mathrm{N}=51)$, Indian $(\mathrm{N}=45)$ and others $(\mathrm{N}=21)$. Most of the students were studying as undergraduate $(\mathrm{N}=326)$, postgraduate $(\mathrm{N}-24)$.

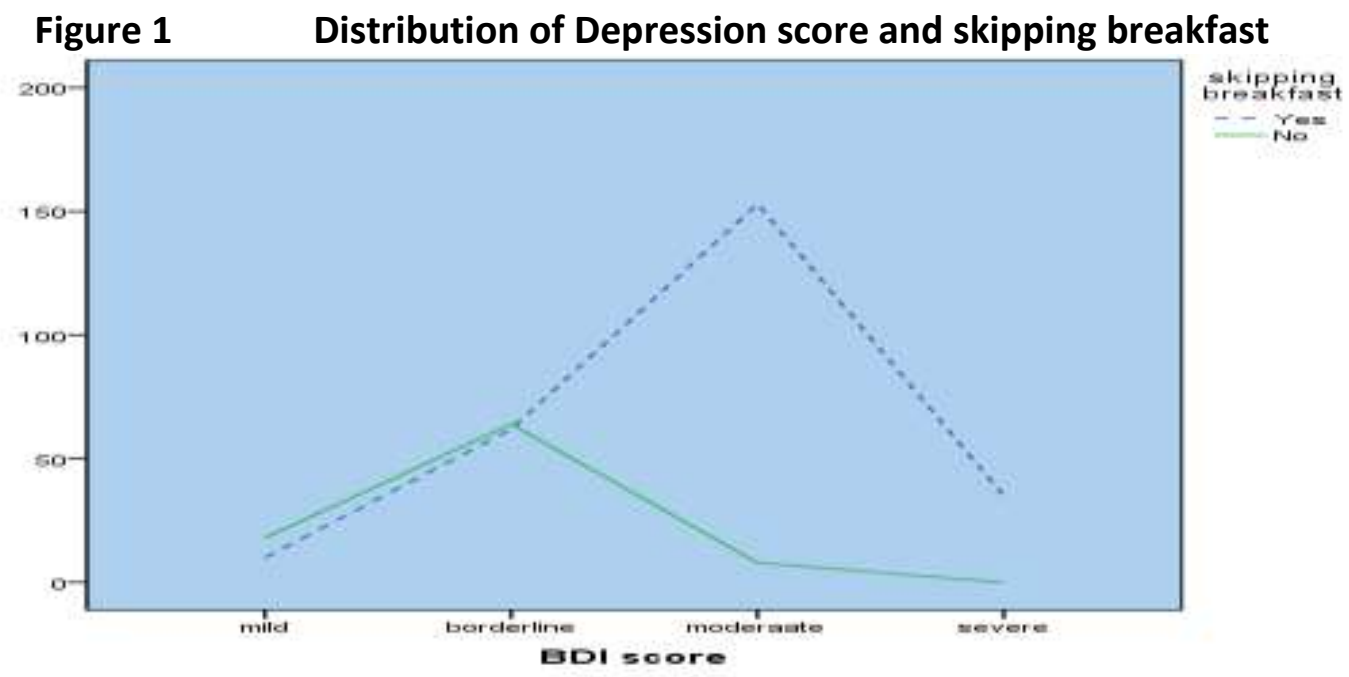

The figure revealed that, most of the students skipped their breakfast more than three times in a week, reported borderline (37\%), moderate(87\%) to severe (20\%) depression . Skipping breakfast is a rising trend attributable to social change and reduced breakfast portions (Kim, 2015). According to the Korean National Health and Nutrition Examination Survey (KNHANES), the rate of skipping breakfast rose from $21.4 \%$ in 2011 to $23.9 \%$ in 2013 (Korea Centres for Disease Control Prevention, 2014). As breakfast consumption is known to be associated with reduced cortisol production (Smith, 2002), which is related to moods, and has been linked to prevention of suicide among children (Wong \& Chiu, 2015), it is important to investigate the association between breakfast consumption and depression. However, very few studies have investigated the association between breakfast consumption and depression or mental health. Most of these studies have focused on a specific age group like children, adolescents, or seniors (Lesani, Mohammadpoorasl, Javadi, Esfeh, 2016). Additionally, considering that socioeconomically disadvantaged group tends to have a higher breakfast skipping rate (Siega-Riz, Popkin, \& Carson, 2000), the association between breakfast and mental health by socioeconomic status must be investigated. Therefore, this study attempts to examine the association between the frequency of breakfast consumption and depression among adults aged 20 years or above, and the association between the frequency of breakfast consumption and depression by socioeconomic factors including age, gender, educational level, household income, and occupation.

The result of this study showed that those who ate breakfast seldom or sometimes were more likely to have depressive symptoms than those who have breakfast always. This finding is consistent with previous studies that have suggested that those who have breakfast on an irregular basis are more likely to have depression (Smith, 2005). Breakfast is significantly important with many healthy advantage, the research suggested that skipping breakfast can contribute in depressive symptoms. Healthy eating behaviour are good contributing factors to increase good mental health. 
INTERNATIONAL JOURNAL OF ACADEMIC RESEARCH IN BUSINESS AND SOCIAL SCIENCES

Vol. 8, No. 8, August 2018, E-ISSN: 2222-6990 @ 2018 HRMARS

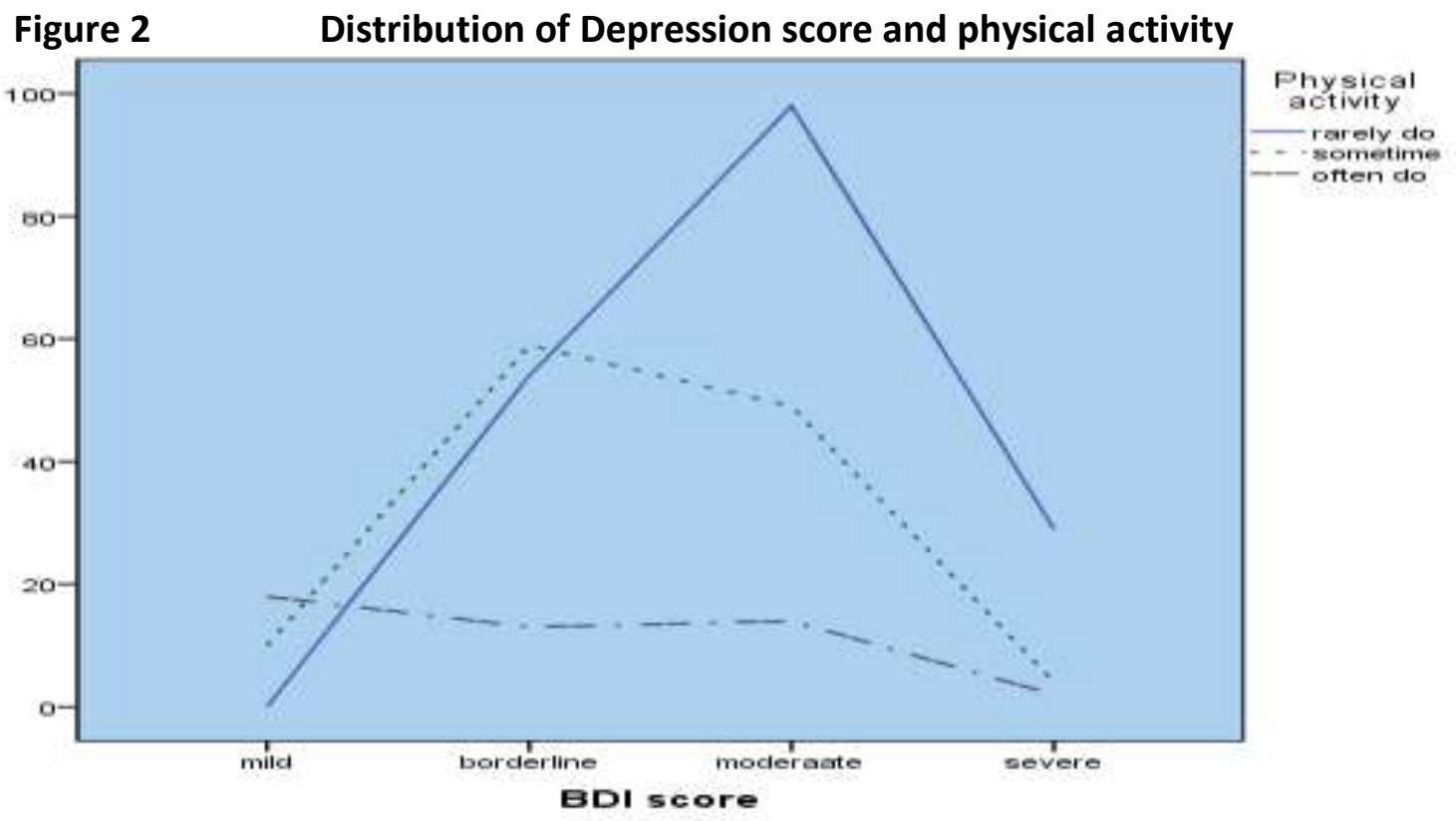

The figure revealed that students, those reported physical activity as rarely do, scored borderline depression (32\%), moderate (55\%) and severe (17\%). Students who reported the sometime do exercise, reported borderline depression (35\%), moderate $27 \%$ ) and severe (2\%). Students doing physical activity often, reported borderline depression (7\%), moderate 9\%) and severe (1\%). Physical activity may play an important role in the management of mild-to-moderate mental health diseases, especially depression and anxiety. Although people with depression tend to be less physically active than non-depressed individuals, increased aerobic exercise or strength training has been shown to reduce depressive symptoms significantly (Huang et al, 2010). However, habitual physical activity has not been shown to prevent the onset of depression. Anxiety symptoms and panic disorder also improve with regular exercise, and beneficial effects appear to equal meditation or relaxation. In general, acute anxiety responds better to exercise than chronic anxiety. Studies of older adults and adolescents with depression or anxiety have been limited, but physical activity appears beneficial to these populations as well. (Paluska and Schwenk, 2000)Excessive physical activity may lead to overtraining and generate psychological symptoms that mimic depression. Several differing psychological and physiological mechanisms have been proposed to explain the effect of physical activity on mental health disorders. Well controlled studies are needed to clarify the mental health benefits of exercise among various populations and to address directly processes underlying the benefits of exercise on mental health. (Kujala et al, 1998). Physical activity is important and significantly increase mental health, regular exercise reduce stress and depression. 
INTERNATIONAL JOURNAL OF ACADEMIC RESEARCH IN BUSINESS AND SOCIAL SCIENCES

Vol. 8, No. 8, August 2018, E-ISSN: 2222-6990 @ 2018 HRMARS

Table 3

Correlation of Depression, breakfast intake and physical activity scores

\begin{tabular}{lllll}
\hline Correlations & & & & \\
\hline & & & $\begin{array}{l}\text { skipping } \\
\text { breakfast }\end{array}$ & Physical activity \\
\hline BDI score & Pearson Correlation & 1 & $-.530^{* *}$ & $-.331^{* *}$ \\
& Sig. (2-tailed) & & .000 & .000 \\
& $\mathrm{~N}$ & 350 & 350 & 350 \\
Breakfast & Pearson Correlation & $-.530^{* *}$ & 1 & $.143^{*}$ \\
& & & & .044 \\
& Sig. (2-tailed) & .000 & & 350 \\
Physical activity & $\mathrm{N}$ & 350 & 350 & 1 \\
& Pearson Correlation & $-.331^{* *}$ & $.143^{*}$ & \\
& Sig. (2-tailed) & .000 & .044 & 350 \\
\hline
\end{tabular}

**. Correlation is significant at the 0.01 level (2-tailed).

*. Correlation is significant at the 0.05 level (2-tailed).

Results shows there is significant negative correlation with depression score and breakfast intake $\left(r=-.530^{* *}\right)$ and depression with physical activity $\left(r=-.331^{* *}\right)$. The result indicate that the students who skip their breakfast are more having high level of depression. Students who regularly doing physical activity and exercise are more like to have low level of depression. There was another study conducted by Wong et al. (2015) revealed that skipping breakfast and lack of social support were associated with physical inactivity. Low beliefs in the health benefits of physical activity, low personal control and knowledge of exercise-heart link, and in women, not trying to eat fibre, low personal mastery and medium personal control were additionally associated with physical inactivity. Practices of unhealthy behaviours are more common in the over-estimation group and the underestimation group compared to the correct estimation group. The over-estimation group performed more unhealthy weight control behaviours such as fasting and eating one food diet, the easy and quick ways to control their weight in a short period of time. However, these practices could increase the risk of anemia, osteoporosis, and dehydration (Sang et al, 2015) and also cause clinical eating disorders (Lim et al, 2015 Breakfast appears to have a regulatory effect on the total daily nutrient and energy consumption (Rampersaud et al. 2005). It has been reported that individuals who skip breakfast eat more sugar, total fat, and cholesterol but less fibre, vitamins, and minerals compared with those who eat breakfast regularly (Schusdziarra et al. 2011). Skipping breakfast has also been associated with adverse cognitive and academic performance, as well as with psychosocial and mood disturbances (Hoyland, Dye, and Lawton 2009). College students who eat a nutritious breakfast have higher school attendance and academic performance and are better at maintaining an appropriate body weight (Rampersaud et al. 2005). The relationship is indicating the need of healthy breakfast eating and doing regular exercise as it is significantly contributing mental health and reducing depression. 
INTERNATIONAL JOURNAL OF ACADEMIC RESEARCH IN BUSINESS AND SOCIAL SCIENCES

Vol. 8, No. 8, August 2018, E-ISSN: 2222-6990 @ 2018 HRMARS

Table 4

Regression Model: Physical activity and skipping breakfast predict depression among University Students

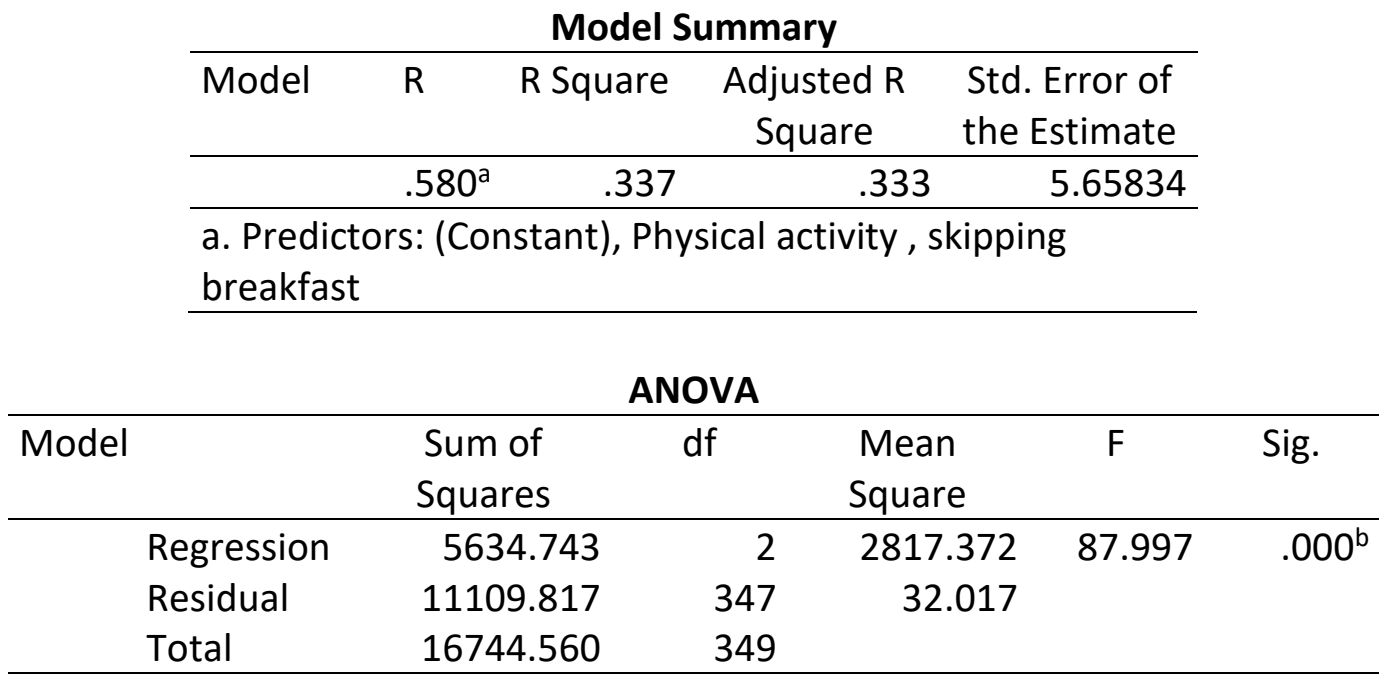

a. Dependent Variable: BDI score

b. Predictors: (Constant), Physical activity, skipping breakfast

Coefficients

\begin{tabular}{|c|c|c|c|c|c|}
\hline \multirow[t]{2}{*}{ Model } & \multicolumn{2}{|c|}{$\begin{array}{l}\text { Unstandardized } \\
\text { Coefficients }\end{array}$} & \multirow{2}{*}{$\begin{array}{c}\begin{array}{c}\text { Standardized } \\
\text { Coefficients }\end{array} \\
\text { Beta }\end{array}$} & \multirow[b]{2}{*}{$\mathrm{t}$} & \multirow[b]{2}{*}{ Sig. } \\
\hline & $\mathrm{B}$ & Std. Error & & & \\
\hline (Constant) & 42.340 & 1.362 & & 31.084 & .000 \\
\hline Breakfast intake & -7.658 & .703 & -.484 & -10.899 & .000 \\
\hline Physical activity & -.343 & .062 & -.247 & -5.563 & .000 \\
\hline
\end{tabular}

a. Dependent Variable: BDI score

Multiple regression was carried out to determine the effect of skipping breakfast, physical activity and depression. There was statistical significance model $(F(2,347=87.99, p<001)$ indicating that the skipping breakfast and physical activity can predict depression score. The adjusted R2 score indicated that $33 \%$ of the variance in the skipping breakfast and physical activity can indicate depression(-.48,-.24). Every score increase in physical activity and breakfast can reduce depression. Results revealed that skipping breakfast and lack of physical activity can effect on symptoms of depression among university students. Breakfast skipping significantly increased the risks of stress and depressive mood. Stress, depressive mood, and suicidal ideation were significantly prevalent as the daily frequency of skipping meals increased. (Gyungjoo et al, 2017) Skipping breakfast can be potentially harmful because breakfast consumption is considered one of the important healthrelated behaviours that benefit physical and mental health. As the rate of depression has increased recently, we investigated the association between the frequency of eating breakfast and depression in adults. Participants who had breakfast seldom or sometimes had higher depressive symptoms than those who always ate breakfast ("seldom") The result of this study suggests that lack of breakfast consumption is associated with depression among adults with different socioeconomic factors. Most 
studies in adolescents have been cross-sectional and have established an association between physical activity and good mental health (Tao et al, 2007).

Many researches has concluded that skipping breakfast and lack of physical exercise can effect negatively the mental health. Ryuji (2018) revealed in study that multivariate logistic regression analysis revealed that insufficient sleep, a poorly balanced diet, snacking between meals and lack of exercise were significantly associated with the prevalence of depressive symptoms, with odds ratio ranging from 1.56 for lack of exercise to 3.98 for insufficient sleep. These results suggest that promoting a healthy lifestyle focused on sleep, food intake and exercise may be important for individuals with depressive symptoms (Shaher \& Hamaideh, 2017). Many researches has concluded that skipping breakfast and lack of physical exercise can effect negatively the mental health. Goodwin (2003) revealed lack of physical activity can predict emotional problems and depression among youngersters. Ryuji (2018) revealed in study that multivariate logistic regression analysis revealed that insufficient sleep, a poorly balanced diet, snacking between meals and lack of exercise were significantly associated with the prevalence of depressive symptoms, (Albertson et al, 2007) with odds ratio ranging from 1.56 for lack of exercise to 3.98 for insufficient sleep. These results suggest that promoting a healthy lifestyle focused on sleep, food intake and exercise may be important for individuals with depressive symptoms. The changes in diet, nutritional status and physical activities have a negative effect on health status (Holmboe, and Wandel, 2012).

study results are indicating that students, now a day's suffering with mental health issues and

among many contributing factors is unhealthy meal, and lack of physical activity . Change in daily routine can help them to increase their mental health.

\section{Contribution of the Study}

This study highlight the significance importance of our first meal intake and physical activities and its effects on good mental health. Student can improve their emotions by engaging in physical activities and taking timely breakfast. This was a small scale study which is helpful to explore more about the contribution of daily living style of students toward their mental and emotional issues.

Limitation: Study was conduct in one University, so we cannot generalize the study results. Further researches with different population are suggest to generalize the significance of the research.

Conclusion: Students who studying in University are facing many challenges as they have to meet every day academic demands. In the process to handle all the demands, they are lacking of proper healthy behaviours to eat meal at time, especially a healthy breakfast and physical activities. This study suggests that there is an association in skipping breakfast, physical activity and depression among students. There has been limited work looking at the relationship between life style behaviours and mental health issues among students.

\section{Acknowledgement}

We acknowledge Sultan Idris Education University department of Research management and innovation center for the research grant.

\section{Corresponding Author}

Dr. Asma Perveen, senior lecture, department of Psychology and counseling. Faculty of Human

Development. Sultan Idris Education University. Email: asmaperveen@fom.upsi.edu.my 
INTERNATIONAL JOURNAL OF ACADEMIC RESEARCH IN BUSINESS AND SOCIAL SCIENCES

Vol. 8, No. 8, August 2018, E-ISSN: 2222-6990 @ 2018 HRMARS

\section{References}

Albertson, A. M., Anderson, G. H., Crockett, S. J. (2007). Ready-to-eat cereal consumption: its relationship with $\mathrm{BMI}$ and nutrient intake of children aged 4 to 12 years. Jouranl Am Diet Association 2007; 103:1613-1619.

Allgöwer, A., Wardle, J., Steptoe, A. (2001). Depressive symptoms, social support, and personal health behaviors in young men and women. Health Psychology, 20(3), 223-227.

Barton, B., Eldridge, A., Thompson, D., Affenito, S., Striegel-Moore, R., Franko, D. (2005). The relationship of breakfast and cereal consumption to nutrient intake and body mass index: The National Heart, Lung, and Blood Institute Growth and Health Study. Journal Am Diet Association 2005; 105:1383-1389.

Beck, A. T. (1996) Beck depression inventory:https://www.bmc.org/sites/ default/files/ For_Medical_Professionals/Pediatric_Resources/Pediatrics_MA_ Center_for_Sudden_Infant_Death_Syndrome_SIDS_Beck-Depression-Inventory-BDI.pdf.

Bruening, M., Eisenberg, M., MacLehose, R., Nanney, M. S. (2013). Relationship between adolescents' and their friends' eating behaviors: breakfast, fruit, vegetable, whole-grain, and dairy Intake. Journal Academy Nutrition Diet; 112:1608-1613.

Deshmukh-Taskar, R., Nicklas, T., O’Neil, C., Keast, D., Radcliffe, J. ( 2006). The relationship of breakfast skipping and type of breakfast consumption with nutrient intake and weight status in children and adolescents: The National Health and Nutrition Examination Survey 19992006. J Am Diet Assoc 2010; 110:869-878.

Dialektakou, K., Vranas, P. (2008). Breakfast skipping and body mass index among adolescents in Greece: whether an association exists depends on how breakfast skipping is defined. J Am Diet Assoc 2008; 108:1517-1525.

Diana, P., Pozuelo-Carrascosa, V., Martinez-Vizcaino, M., Sanchez-Lopez, R., BartolomeGutiérrez, B., Rodríguez-Martín, and Notario-Pacheco, B. (2017). Resilience as a mediator between cardiorespiratory fitness and mental health-related quality of life: A cross-sectional study, Nursing \& Health Sciences, 19, 3, (316-321).

Fujiwara, T. (2003). Skipping breakfast is associated with dysmenorrhea in young women in Japan. International Journal Food Science Nutrition 2003; 54:505-509.

Geoff, P., Lovell, D., Kim, N. (2014) A cross-sectional investigation of depressive, anxiety, and stress symptoms and health-behavior participation in Australian university students: Journal of Nursing and Health sciences.

Goodwin, R. D. (2003). Association between physical activity and mental disorders among adults in the United States. Preventive Medicine, 36(6), 698-703.

Gollub, E. A., \& Weddle, D. O. (2004). Improvements in nutritional intake and quality of life among frail homebound older adults receiving home-delivered breakfast and lunch. Journal of the American Dietetic Association, 104(8), 1227e1235. http://dx.doi.org/10.1016/j.jada.2004.05.204.

Gyungjoo, L., Kyungdo, H., Hyunju, K. (2017). Risk of mental health problems in adolescents skipping meals: The Korean National Health and Nutrition Examination Survey 2010 to 2012: Nursing Outlook, Volume 65, Issue 4, July-August 2017, Pages 411-419 https://doi.org/10.1016/j.outlook.2017.01.007.

Holmboe, O., Wandel, M. (2012). Changes in dietary habits after migration and consequences for health: a focus on South Asians in Europe Food Nutrition Research , 56 (10) (2012), pp. 1-13 http://dx.doi.org/10.3402/2Ffnr.v56i0.18891. 
INTERNATIONAL JOURNAL OF ACADEMIC RESEARCH IN BUSINESS AND SOCIAL SCIENCES

Vol. 8, No. 8, August 2018, E-ISSN: 2222-6990 @ 2018 HRMARS

Hoyland, A., Dye, L., Lawton, C. L. (2009). A systematic review of the effect of breakfast on the cognitive performance of children and adolescents. Nutrition Research Reviews, 22(2), 220e243. http://dx.doi.org/10.1017/ S0954422409990175.

Hoyland, A., Dye, L., and Lawton, C. L. (2009). A systematic review of the effect of breakfast on the cognitive performance of children and adolescents. Nutrition Research Reviews 22:220-43. doi:10.1017/S0954422409990175.

Huang, C., Hu, H., Fan, Y., Liao, Y., Tsai, P. (2010). Associations of breakfast skipping with obesity and health-related quality of life: Evidence from a national survey in Taiwan. International Journal of Obesity (London), 34(4), 720e725. http:// dx.doi.org/10.1038/ijo.2009.285.

Hussein, R., Ashqan, B., Jamalallail, R., Alafeef, A. (2013). Knowledge, attitude, and behavior of young women towards dietary calcium intake. Life Sci J 2013; 10:2491-2496.

Kim, J. (2015). Health-related quality of life according to breakfast in elderly. Journal of the Korea Academia-Industrial Cooperation Society, 16(7), 4668e4678.

Korea Centers for Disease Control Prevention. (2014). Korea health statistics 2013. Korea national health and nutrition examination survey(KNHANES V-1). Seoul: Korea Centers for Disease Control and Prevention.

Kujala, U. M., Kaprio, J., Sarna, S. (1998). Relationship of leisure-time physical activity and mortality: the Finnish twin cohort. JAMA 1998; 279: 440-4.

Lee, G., Ha, Y., Vann, J., Choi, E. (2009). Weight perception and dieting behavior among Korean adolescents. Journal School Nursing. 2009;25(6):427-35.

Lesani, A., Mohammadpoorasl, A., Javadi, M., Esfeh, J. M., Fakhari, A. (2016). Eating breakfast, fruit and vegetable intake and their relation with happiness in college students. Eating and Weight Disorders-Studies on Anorexia, Bulimia and Obesity.

Lim, Y. S., Park, N. R., Jeon, S. B., Jeong, S. Y. (2015). Analysis of Weight Control Behaviors by Body Image Perception among Korean Women in Different Age Groups: Using the 2010 Korea National Health and Nutrition Examination Survey Data. Korean J Community Nutrition. 2015;20(2):141-50.

Nicklas, T. A., Reger, C., Myers, L., O’Neil, C. (2000). Breakfast consumption with and without vitamin-mineral supplement use favorably impacts daily nutrient intake of ninth-grade students. Journal Adolescent Health 2000; 27:314-321.

Paluska, A. S., and Schwenk, L. (2000). Physical Activity and Mental Health: Sports Medicine, March 2000, Volume 29, issue 3, pp 167-180.

Rahkonen, K., Kaprio, J., Rissanen, A., Virkkunen, M., Rose, R. (2003). Breakfast skipping and healthcompromising behaviors in adolescents and adults. Europe Journal Clinical Nutrition 2003; 57:842-853.

Rampersaud, G. C. (2009). Benefits of breakfast for children and adolescents: update and recommendations for practitioners. Am J Lifestyle Med 2009; 3:86-103.

Rampersaud, G., Pereira, M., Girard, B., Adams, J., and Metzl, J. (2005). Breakfast habits, nutritional status, body weight and academic performance in children and adolescents. Journal of the American Dietetic Association 105:743-60. doi:10.1016/j.jada. 2005.02.007.

Rihmer, Z., Angst, A. (2004). Mood disorders: Epidemiology. In: Sadock BJ, Sadock VA, editors. Comprehensive Textbook of Psychiatry. 8th ed. Baltimore: Lippincott Williams and Wilkins.

Sagar, A. (2005). Long term health risks due to impaired nutrition in women with a past history of bulimia nervosa. Nutrition Noteworthy, 7(1). 
INTERNATIONAL JOURNAL OF ACADEMIC RESEARCH IN BUSINESS AND SOCIAL SCIENCES

Vol. 8, No. 8, August 2018, E-ISSN: 2222-6990 @ 2018 HRMARS

Schusdziarra, V., Hausmann, M., Wittke, C., Mittermeier, J., Kellner, M., Naumann, A., Wagenpfeil, S., and Erdmann, J. (2011). Impact of breakfast on daily energy intake ananalysis of absolute versus relative breakfast calories. Nutrition Journal 10 (5):1-8. doi:10.1186/ 1475-2891-10-5.

Shaher, H., Hamaideh, A. (2017). Among Jordanian university students: Its prevalence and correlates with depression, anxiety, stress, and demographics, Perspectives in Psychiatric Care, 54, 2, (274-280).

Siega-Riz, A. M., Popkin, B. M., \& Carson, T. (2000). Differences in food patterns at breakfast by sociodemographic characteristics among a nationally representative sample of adults in the United States. Preventive Medicine, 30(5), 415e424.

Smith, A. P. (2005). The concept of well-being: Relevance to nutrition research. British Journal of Nutrition, 93 (Suppl 1), Session 5. global burden of disease study 2010. Lancet 380 (9859):2224-60. doi:10.1016/S0140-6736 (12)61766-8.

Supa, P., Karl, P., Hemant, K., Kassean. (2015). Physical inactivity and associated factors among university students in 23 low-, middle- and high-income countries. International Journal of Public Health: July 2015, Volume 60, Issue 5, pp 539-549.

Tao, F., Xu ,M., Kim, S., Sun ,Y., Su, P., Huang, K. (2007). Physical activity might not be the protective factor for health risk behaviours and psychopathological symptoms in adolescents. Journal Pediatric Child Health. 2007, 43: 762-767. 10.1111/j.1440-1754.2007.01217.x.

The World Health Report. (2014). Prevalence of depression. Available from: http://www.who.int/whr/2001/en/

Vereecken, C., Dupuy, M., Rasmussen, M., Kelly, C., Nansel, T. R., Al Sabbah, H. (2010).Breakfast consumption and its sociodemographic and lifestyle correlates in schoolchildren in 41 countries participating in the HBSC study. Int J Public Health 2010; 54 (Suppl 2):180-190.

Watkins, C., Daniels, L., Jack, C., Dickinson, H., \& van den Broek, M. (2001). Accuracy of a single question in screening for depression in a cohort of patients after stroke: Comparative study. BMj, 323(7322), 1159.

Weddle, D., Gollub, E., Stacey, S., \& Wellman, N. (1998). The morning meals on wheels pilot program: The benefits to elderly nutrition program participants and nutrition projects. Miami: National Policy and Resource Center on Nutrition and Aging.

Williams, P. (2007). Breakfast and the diets of Australian children and adolescents: an analysis of data from the 1995 national nutrition survey. International Journal Food Science Nutrition; 58:201-216.

Wong, W., \& Chiu, I. W. (2015). The impact of habit of eating breakfast and physical activity on children suicidal behaviour. International Journal of Behavioral Research \& Psychology, 3(4), $99 \mathrm{e} 104$.

World Health Organization. (2015). Depression among students. http://www.who.int/. 